\title{
Ionic Liquid Mediated Processing of Lignocellulosic Biomass and their Fractionation using Membrane Separation
}

\author{
Gayatri Gogoi ${ }^{1,2}$ and Swapnali Hazarika ${ }^{1,2 *}$ \\ ${ }^{1}$ Division Engineering Science and Technology Division (ESTD), CSIR North East Institute of Science \& Technology, India \\ ${ }^{2}$ Academy of Scientific and Industrial Research, CSIR NEIST Campus, India
}

Submission: April 15, 2019; Published: July 02, 2019

*Corresponding author: Swapnali Hazarika, Chemical Engineering Group, Engineering Science and Technology Division (ESTD) \& Academy of Scientific and Industrial Research, CSIR NEIST Campus Jorhat-785006, Assam, India

\begin{abstract}
Lignocellulosic biomass provides alternative and renewable energy resources for sustainable production of organic fuels and chemicals. The deconstruction of lignocellulosic biomass is very difficult due to its complex, intricate and rigid structure formed by several covalent and noncovalent interactions. However, the ionic liquid technology on biomass processing is recently gaining importance over the other conventional methods due to the unique properties of ILs. This review focuses on the recent studies on biomass dissolution in several ILs for the fractionation and recovery of lignocellulosic components such as cellulose, hemicelluloses and lignin. The review further considers the influence of several crucial parameters that governs the dissolution process. This study also focuses on the role of membrane technology for separation and purification of lignin. As ionic liquids are very expensive therefore its recovery and reuse are necessary, and this study also emphasizes the use of nanofiltration for recovery of ILs.
\end{abstract}

Keywords: Lignocellulosic biomass; Deconstruction; Fossil fuel; Renewable energy; Cellulose; Hemicelluloses; Biodiversity

\section{Introduction}

The efficient utilisation of biomass is becoming increasingly important as it provides unique resources for sustainable production of bioproducts. Lignocellulosic biomass is also a promising alternative and renewable energy source being used as replacement for fossil fuel. Lignocelluloses, essentially the cell wall material of plants, is a porous micro-structured composite mainly consisting of cellulose, hemicelluloses and lignin $[1,2]$. It has been projected that lignocellulosic biomass has the potential to be a large scale, low cost and sustainable feedstock for renewable fuels and chemicals [3,4]. Lignocellulosic biomass from agricultural residues, forestry wastes, wastepaper and crops which is a renewable, relatively carbon- neutral source of energy has come under intense research scrutiny due to its potential use as a starting material for bioproducts from biofuels to specialty chemicals [3-5]. North eastern region of India is one of the hotspot biodiversity of the world that provides abundant lignocelluloses for processing and thereby recovery of value-added products. Lignocellulosic biomass contains $\sim 30-50 \%$ cellulose, a glucose polymer; $10-40 \%$ hemicelluloses, a sugar heteropolymer and $\sim 5-30 \%$ lignin, a non-fermentable phenyl propene unit plus lesser amounts of minerals, oils, soluble sugars, and other components $[6,7]$. The dense network of intramolecular / intermolecular hydrogen bonds in cellulose, branched hetero polysaccharides of hemicelluloses with shorter chain lengths and three-dimensional amorphous lignin provides a complex network in lignocellulosic biomass [8-10]. Because of this, new and efficient solvents and process technologies are needed to break the complex network of lignocellulosic biomass. Heating reflux extraction, soxhlet extraction or maceration at room temperature are the common methods used for the extraction of value-added products from biomass. However, these procedures are laborious, time and energy consuming and sometimes require complex equipment and the use of toxic volatile organic compounds. Hence the development of alternative and novel methods for extraction and recovery of value-added products from biomass remains a crucial challenge. Thus, ionic liquids have attracted considerable interests over the last several years as a new class of environmentally benign solvent for extraction and separation of value-added products from biomass. Ionic liquid serves as a new class of designer solvents that can dissolve many biomacromolecules such as cellulose, lignin, silk fibroin, starch etc with high efficiency [11-13].

As an environment friendly material, the applications of ionic liquids have been extensively reported as solvent to facilitate green applications in reactions and separations due to their unique ben- 
eficial properties usually negligible vapour pressure, low flammability, high thermal stability over a wide range of temperatures and tuneable properties such as hydrophobicity, polarity and solvent power etc [14-18]. The unique properties of ionic liquids make them an excellent choice for the extraction and separation of value-added products from biomass $[12,19,20]$. Ionic liquids are regarded as "designer solvents" because their physical properties can be modified according to the nature of the desired reactions by modifications of their cations and anions. These unique nature of ionic liquids increases their potential applications in extracting bioactive natural compounds in separation processes. Using ionic liquids as solvents in extracting bioactive natural compounds from biomass not only leads to a green process, but also improves the extraction efficiency from a thermodynamic point of view. In addition to the large applications of ionic liquids they are also able to form aqueous biphasic systems (ABS) which have important biotechnological applications for the separation and purification of vital biomolecules [21,22].

At the same time advances in material science and membrane manufacturing technology have made membrane technology grow to be an energy efficient excellent technology for separation of value-added products. Membrane based separation processes are economical, safe and eco-friendly and it is an alternative to conventional processes. Energy required for some large-scale operations in conventional process can be decreased by an order of magnitude through membrane-based process. There is a potential application of membrane technology in recovery and purification of value-added compounds using microfiltration, ultrafiltration, nanofiltration and other membrane processes. The membrane separation technique is a pressure-driven process normally applicable for separation of dissolved components. Therefore, efforts are be directed to modify the structure and chemistry of membranes and to developed suitable membrane systems for product recovery. Since ILs are very expensive than the conventional solvents and hence the recycling and reuse of the ionic liquids after use is a crucial factor for the economic efficiency of the extracting value-added products with ionic liquids. Therefore, this research programme aims at the use of membrane technology for the recovery of the ionic liquids for further processing.

\section{Processing of Lignocelluloses in Ionic Liquids}

The field of biomass dissolution using ionic liquids started with dissolving cellulose. Initially the dissolution of cellulose in ionic liquids have attracted much more attention than the other components of biomass. However later to use ILs in industrially relevant biomass related process, a thorough understanding of the interaction of ILs with all the components of biomass, viz., cellulose, hemicellulose and lignin were achieved. The fact that ILs could dissolve cellulose was first discovered back in 1934 using pyridine-based salts [23]. But due to the high melting point of the salt and lack of understanding of the salt chemistry at that time the work was regarded to have no practical applications. Later in 2002 with the discovery of new imidazolium based ILs, there have been many studies on the processing of lignocellulosic biomass in dialkylated imidazolium based ILs with different anions [17, 2433].

Initially Swatloski et al. [14] demonstrated the mechanism of dissolution of isolated cellulose in ILs. Isolated cellulose was dissolved in nine imidazolium based ILs with different properties from which 1-butyl-3 methyl imidazolium chloride emerged as the most efficient IL in dissolving isolated cellulose. Later in 2005 Zhang et al. [16] carried out work on the IL 1-allyl-3-methyl imidazolium chloride as new and powerful non-derivatizing solvent for cellulose. In 2006 Dadi et al. [34] assessed the saccharification of cellulose regenerated from IL pre-treatment.

Later the ability of certain imidazolium based ILs were investigated for the dissolution of native cellulose from biomass. Initially Fort et al. [17] demonstrated that solvent system [BMIM]Cl/ DMSO is capable of dissolving woodchips partially. Kilpelainen et al. [24] carried out experiments for complete dissolution of dried wood sawdust samples (Norway spruce and Southern pine) in both $[\mathrm{BMIM}] \mathrm{Cl}$ and $[\mathrm{AMIM}] \mathrm{Cl}$ at temperatures ranging from $80^{\circ} \mathrm{C}$ to $130^{\circ} \mathrm{C}$. It was observed that the complete dissolution of wood in ILs was attributed to the water content, particle size of the wood sample and temperature and time of the dissolution process. Water content significantly reduces the solubility of wood in ILs and smaller particles were reported to favour the dissolution. While higher temperature as well as larger reaction time favours the dissolution of wood in ILs. Sun et al. [28] demonstrated that [EMIM] $\left[\mathrm{CH}_{3} \mathrm{COO}\right]$ is capable of dissolving both softwood (Southern yellow pine) and hardwood (Red oak). In their work it was found that more than $90 \%(\mathrm{w} / \mathrm{w})$ of the added wood was dissolved at $110^{\circ} \mathrm{C}$ within 16hours and concluded that $[\mathrm{EMIM}]\left[\mathrm{CH}_{3} \mathrm{COO}\right]$ is more efficient in dissolving biomass than [BMIM]Cl and [AMIM]Cl. Meanwhile Zavrel et al. [35] studied on high throughput screening of six different ILs dissolving lignocelluloses. They found that [EMIM] $\mathrm{Cl}$, [BMIM] $\mathrm{Cl}$ and [EMIM] $\left[\mathrm{Et}_{2} \mathrm{PO}_{4}\right]$ were only able to partially dissolve different wood chips (spruce, silver fir, common beech and chest nut) while [EMIM] $\left[\mathrm{CH}_{3} \mathrm{COO}\right]$ was defined as the most efficient for dissolving cellulose and [AMIM]Cl was regarded as the most suitable for biomass dissolution. Lee et al. [17] demonstrated a low solubility of wood flour and a high solubility of microcrystalline cellulose in $[\mathrm{EMIM}]\left[\mathrm{CH}_{3} \mathrm{COO}\right]$ proving that presence of lignin restricts the solubility of wood flour in this IL. Singh et al. [29] demonstrated that [EMIM] $\left[\mathrm{CH}_{3} \mathrm{COO}\right]$ is capable of dissolving completely all the major components of switchgrass at 3 hours in $120^{\circ} \mathrm{C}$. Later, studies proved that $[\mathrm{BMIM}]\left[\mathrm{CH}_{3} \mathrm{COO}\right]$ is able to dissolve poplar wood with a dissolution yield of $96 \mathrm{wt} \%$ at $130^{\circ} \mathrm{C}$ after 12 hours while [BMIM]Cl achieved only $23 \mathrm{wt} \%$ of poplar dissolution [36]. In the dissolution of sugarcane bagasse [EMIM] $\left[\mathrm{CH}_{3} \mathrm{COO}\right]$ was found to be more efficient than other ILs such as [BMIM][DEP] [37].

\section{Influence of ILs in biomass dissolution}

The ability of ILs for dissolution of biomass are evaluated in this research area considering various parameters such as, cation, anion, length of alkyl substituent on cation, hydrophobicity and hydrophilicity of the ionic liquids used. Initial investigations 
show that combination of 1-butyl-3-methyl imidazolium cation with chloride anion is most effective for cellulose dissolution while non chloride anions such as $\mathrm{BF}_{4}^{-}$and $\mathrm{PF}_{6}{ }_{6}^{-}$are not effective in dissolving cellulose [14]. This study also reported that [AMIM] $\mathrm{Cl}$ can swell cellulose at room temperature. Simmons et al. [38] carried out study on cellulose dissolution using ILs with seven cations in combination with eighteen anions according to which [AMIM][HCOO] can dissolve $21 \%$ cellulose while IL with bulkier cation, benzyl-dimethyl tetradecyl ammonium chloride shows a higher dissolution of cellulose (39\% mass). The study also shows that lignin dissolution is predominant in ILs with methyl sulphate or methyl sulfonate anions.

Due to the higher corrosivity and viscosity of the halides, halide free ILs with high hydrogen bond basicity have been successfully employed in the dissolution of cellulose. Fukaya et al. [39] demonstrated that low viscosity [AMIM] [HCOO] dissolves 20\% mass of microcrystalline cellulose whereas [AMIM]Cl dissolve only $2 \%$ under the same conditions. Halide free ILs with varying phosphonate anions were also found to be good cellulose solvents at mild temperature. Thus, it is observed that ILs containing bulky cation and halide anion may decrease the concentration of active chloride ion and thus the solvating capacity for both cellulose and lignin is reduced [14].

To understand the ability of ILs for dissolution of lignocellulosic biomasses, the use of polarity approach can be considered. In this regard the quantitative Kamlet-Taft parameters are broadly used in literature and is a useful tool to predict the pre-treatment efficiency of certain ILs in disrupting lignocelluloses $[40,41]$. From Kamlet-Taft parameters it was found that anion basicity influences the lignocellulosic biomass dissolution. A correlation is obtained between higher dissolution capacities of ILs and higher value of $\beta$ parameter. ILs with a strong hydrogen bond basicity are effective in weakening the hydrogen bonding network of the lignocellulosic matrix [42]. Brandt et al. [42] demonstrated high dissolution power for [BMIM] $\left[\mathrm{CH}_{3} \mathrm{COO}\right],[\mathrm{BMIM}] \mathrm{Cl}$ and [BMIM] [DMP] and observed that acetate-based IL is the most effective for swelling and dissolution which is due to a high $\beta$ value exhibited by $\left[\mathrm{CH}_{3} \mathrm{COO}\right]$ anion. The increased basicity of the $\left[\mathrm{CH}_{3} \mathrm{COO}\right]$ anion makes it more efficient at disrupting the inter- and intramolecular hydrogen bonding in lignocellulosic matrix than the other anions. ILs with anions having lower hydrogen bond basicity, such as [BMIM] $\left[\mathrm{MeSO}_{4}\right],[\mathrm{BMIM}]\left[\mathrm{HSO}_{4}\right]$ and $[\mathrm{BMIM}]\left[\mathrm{MeSO}_{3}\right]$ are unable to perform complete dissolution of biomass as the interction is weak in the lignocellulosic matrix. ILs not only disrupt the hydrogen bonding of crystalline cellulose of lignocelluloses but also interact and solvate the aromatic characters of lignin by п-п and n-п interactions, performed by the IL cation $[43,44]$.

\section{Mechanism of Dissolution of Lignocellulose in Imidazolium based ILs}

Studies shows that the main force involved in the dissolution of LCB in IL is hydrogen bonding while electrostatic and van der waals forces are of minor importance [45]. Although the mecha- nism of cellulose in ILs is not fully understood, there are evidences regarding the role of cation and anion in the disruption of hydrogen bonding of cellulose. ${ }^{13} \mathrm{C}$ NMR and ${ }^{35 / 37} \mathrm{Cl} \mathrm{NMR}$ relaxation studies indicated that there is a 1:1 stoichiometric interaction between the chloride ions in [BMIM] $\mathrm{Cl}$ and the hydroxyl groups in cellulose [46]. Electron- donor- acceptor interactions between the IL anion and the cellulose hydroxyl hydrogens and between the IL cation and cellulose hydroxyl oxygens have been proposed $[16,47,48]$.

This model of cellulose dissolution in IL shows that hydroxyls participating in this interaction are primarily the C-6 and C-3 [49]. Zhang et al. [48] demonstrated the EDA interactions for [EMIM] $\mathrm{OAc}$ and cellulose employing ${ }^{13} \mathrm{C}$ NMR. They also suggested that the acetate anion favours the formation of hydrogen bonds with hydrogen atoms of hydroxyls, and the aromatic protons in the bulky imidazolium cation especially the most acidic proton at the C-2 position, prefer to associate with the oxygen atoms of hydroxyls with less steric hindrance. Amongst the imidazolium ILs that have been explored for dissolution of either cellulose or whole biomass, [BMIM]Cl has been found to most effective in dissolving cellulose and [EMIM]OAc has been most effective in dissolving wood, i.e., partial delignification along with dissolution of cellulose [50].

Lignin is more difficult to be dissolved in ILs than the other components of lignocellulose because of its strong covalent bonds and complex structure. Although ILs that are capable of dissolving cellulose are also often capable of dissolving lignocellulose lignin, but solvent properties of ILs for effectively dissolving lignin are slightly different. The exact mechanism behind the role of anion in dissolving /extracting lignin is not fully understood but some speculations exist regarding the role of cation. Theoretical modelling has shown that cations based on imidazole are well suited for dissolving lignin since the cation can favourably interact with aromatic phenyl rings of lignin [51].

ILs with anions having high basicity is well known major criteria to effectively dissolve cellulose while mid-range basic anions are the best for dissolving lignin. This includes anions like methylsulfate, hydrogen sulfate, trifluoromethanesulfonate and halides. However, acetate anion besides having high basicity is effective for dissolving lignin. George et al. [52] reported that combination of both IL cation and anion effects the macromolecular structure of lignin. They reported that IL anions influences the degree of lignin structural modification in the order as,

Sulphates $>$ lactate $>$ acetate $>$ chloride $>$ phosphates

In contrast Pu et al. [53] demonstrated that solubility of lignin is mainly influenced by the nature of the anion. They studied the dissolution of lignin isolated from a southern pine kraft pulp in some ILs, including 1,3-dimethyl imidazolium methylsulfate [MMIM] $\mathrm{MeSO}_{4}$, 1-hexyl-3-methyl imidazolium trifluoromethane sulfonate [HMIM] $\mathrm{CF}_{3} \mathrm{SO}_{3}$ 1-butyl-2,3-dimethyl imidazolium tetrafluoroborate [BMIM] $\mathrm{BF}_{4}$, 1-butyl-3-methyl imidazolium hexafluorophosphate [BMIM] $\mathrm{PF}_{6}$ etc. It was observed that softwood lignin is dissolved in [MMIM] $\mathrm{MeSO}_{4}$ and [BMIM] $\mathrm{MeSO}_{4}$ at room tem- 
perature. For IL containing $\left[\mathrm{BMIM}^{+}\right.$as the cation they found the order of the solubilities of lignin followed the order as,

$$
\left[\mathrm{MeSO}_{4}\right]^{-}>\mathrm{Cl}^{-}>\mathrm{Br}^{-}>>\mathrm{PF}_{6}
$$

Therefore, it was concluded that anions of ILs have important effects on the dissolution of lignin.

A recent study by Liu et al. [54] demonstrated that the cation and anion both takes part in the dissolution of cellulose. They studied the dissolution mechanism of [EMIM]OAc and found that there is a change in conformation of the oligomers and the rotamers in cellulose that explains the regeneration of cellulose in imidazolium based ILs. Binder at al. [55] proposed mechanisms for acid catalysed delignification in several ILs that proceeds via the formation of Hibberts' ketones.

\section{Factors Effecting Biomass Dissolution}

Along with the dependence on the type of IL, for specific interactions between ILs and biomass several reaction conditions such as temperature, time, particle size of biomass etc also effects the biomass dissolution in ILs.

\section{Effect of temperature}

In general, temperature increase accelerates swelling and dissolution rates of lignocelluloses in ILs which is due to the destabilisation effect of temperature on the hydrogen bonds in the three-dimensional cellulosic structure $[28,35,42,43]$. On decreasing temperature longer time is required for an efficient swelling and dissolution of biomass. Wang et al. [43] studied the effect of temperature on dissolving wood chips in [AMIM]Cl. He observed that at temperature below $50^{\circ} \mathrm{C}$ the wood sample had the same structure as the original structure while at $70^{\circ} \mathrm{C}$ the swelling of the wood chips occurs, and dissolution occurs at $100^{\circ} \mathrm{C}$. On increasing temperature to $120^{\circ} \mathrm{C}$ the dissolution rate increases. A study on dissolution of sugarcane bagasse in [bmim $] \mathrm{Cl}$ at different temperatures $\left(110-160^{\circ} \mathrm{C}\right)$ showed that below $150^{\circ} \mathrm{C}$ the crystallinity of cellulose rich regenerated product is slightly lower than that of original material [56]. Arora et al. [12] used temperature from 110 to $160^{\circ} \mathrm{C}$ for 3 hours pre-treatment of switchgrass using [EMIM]Cl. It was observed that sugar yield increases with temperature with a maximum yield at $160^{\circ} \mathrm{C}$ which is 12 times higher than that observed at $110^{\circ} \mathrm{C}$.

High temperature is beneficial for lignin extraction in ILs. Tan et al. [57] observed that delignification of sugarcane bagasse increases in alkyl benzene sulphonate IL with increasing temperature from $170^{\circ} \mathrm{C}$ to $190^{\circ} \mathrm{C}$. The same trend is also observed in wood flour and triticale straw using [EMIM]OAc [17,27]. Although higher temperatures favour the pre-treatment efficiency but at the same time it results in more degradation of carbohydrates and ILs themselves, as well as in modification of lignin properties. At the same time consumption of higher energy (using elevated temp) is a drawback for sustainable and economic processes. Therefore, depending upon the biomass type and IL used the choice of temperature must be considered and optimised.

\section{Reaction time effect}

For an efficient pre-treatment of biomass in IL, duration of time is related to the applied temperature. It is reported from several studies that good results are expected with simultaneous short duration and high temperature or longer duration at lower temperature. Sun et al. [28] observed that on treatment of southern yellow pine and red oak in $[\mathrm{EMIM}]\left[\mathrm{CH}_{3} \mathrm{COO}\right]$ at $110^{\circ} \mathrm{C}$, complete dissolution occurs after 46 hours and 25 hours respectively. However along with the improved dissolution capacity there occurs degradation of either dissolved biocomponents or the ILs in longer pre-treatment time. Peroza et al. [58] studied the pre-treatment of corn Stover, wheat straw and eucalyptus in [EMIM]Cl at $150^{\circ} \mathrm{C}$ and found that $1 \mathrm{~h}$ pre-treatment time led to significantly higher glucose and xylose yields compared with $0.5 \mathrm{~h}$ pre-treatment.

However, the opposite trend was found for Lenga (Nothofagus pumilio) which is due to smaller size of the biomass that leads to faster IL pre-treatment. Xu et al. [59] Studied the effect of pre-treatment time of corn Stover in [EMIM] $\left[\mathrm{CH}_{3} \mathrm{COO}\right]$ at a relatively low temperature of $70^{\circ} \mathrm{C}$ and observed that longer pre-treatment ( $24 \mathrm{hrs}$ of pre-treatment) enhances the glucose and xylose yield ( $84.9 \%$ and $64.8 \%$ respectively). Fu et al. [27] investigated the effect of pre-treatment time of triticale straw in [EMIM] [CH$\left.{ }_{3} \mathrm{COO}\right]$ for lignin removal at $90^{\circ} \mathrm{C}$ and observed that a pre-treatment of $24 \mathrm{~h}$ was enough for complete cellulose hydrolysis.

\section{Effect of Biomass particle size}

Particle size of biomass is one of the crucial parameters in the pre-treatment of lignocelluloses in ILs since it directly impacts on the contact and diffusion of ILs into the lignocellulosic materials $[60,61]$. In theory, smaller particle size increases the available biomass surface area and increases the IL diffusion into the lignocellulosic material although the perfect size depends on the biomass type and chosen ILs.

Kilpelainen et al. [24] demonstrated that dissolution of smaller particles of wood chips is more suitable during pre-treatment process. The increased surface area of the smaller particles and the increase of mechanical pulping that breakdowns the internal structure improves the efficiency of biomass pre-treatment. Bahcegul et al. [62] studied the effect of four different particle sizes of cotton stalks $(<0.15 \mathrm{~mm}, 0.15-0.5 \mathrm{~mm}, 0.5-1.00 \mathrm{~mm}$ and 1.0-2.00mm) on [EMIM] [ $\left.\mathrm{CH}_{3} \mathrm{COO}\right],[\mathrm{EMIM}] \mathrm{Cl}$ pre-treatment. On pre-treatment with $[\mathrm{EMIM}]\left[\mathrm{CH}_{3} \mathrm{COO}\right]$ higher efficiency was obtained with the smallest particle size. Nguyen et al. [63] studied the effect of particle size on pre-treatment of rice straw and observed that cellulose recovery decreases in the smallest particle size samples although it was like medium and highest size particle.

\section{Dissolution of Lignocellulosic Biomass in Ionic Liquid-Water Mixture}

This is a novel approach in the field of processing of lignocellulosic biomass in ionic liquids. An ionic liquid-water mixture for 
dissolution of lignocelluloses is a promising method because of several advantages such as

a) smaller amount of IL is required that reduces the cost,

b) provides easier biomass processing operations because of its reduced viscosity and

c) facilitates the recycling of IL from the mixture instead of pure IL [68-71] [64-67].

Zhang et al. [68] reported that significantly high $\mathrm{K}_{\mathrm{w}}$ of IL-water mixture was achieved which is responsible for the conversion of cellulose without acid catalysis. Ma et al. [69] found that [BMIM] $\mathrm{Cl}$-water mixture can quickly dissolve the lignin and xylan while slowly dissolves the cellulose. Thus, the difference in solubilities of cellulose and lignin in [BMIM]Cl-water mixture provides the possibility of separating biomass components. Fu \& Mazza [64] reported that [EMIM]OAc -water mixture can effectively dissolve the lignin. Zhang et al. [70] reported that IL-water mixture plays important role during pre-treatment and delignification. The effectiveness of IL-water mixtures for deconstruction of biomass and delignification can be estimated from the solution $\mathrm{pH}$ and it was observed that the effectiveness of a mixture of water and [BMIM] $\mathrm{MeSO}_{3}(\mathrm{pH} \mathrm{0.9)}$ to deconstruct and delignification is higher than that of a mixture of water and [BMIM]Cl (pH 5.9) or [EMIM] $\mathrm{Cl}$ (pH6). Brandt et al. [2] defined the treatment of lignocellulosic biomass using ionic liquid - water mixture as "Ionosolv Process" characterised by delignifying biomass through dissolution of lignin. Doherty et al. [30] performed pre-treatment of wood flour in 5 and $10 \%(w / w)$ of water with [EMIM]OAc, [BMIM]OAc and [BMIM] $\mathrm{MeSO}_{4}$. It was observed that after $12 \mathrm{hrs}$ at $90^{\circ} \mathrm{C}$ with increased addition of water a decrease in glucose and xylose yields was observed and described that added water displayed a moderate inter-crystalline swelling effect. The crystallinity and lignin content of the pre-treated wood flour were found to be higher than that with pure ILs which shows that the addition of water decreases the ability of the ILs to disrupt the crystallinity of cellulose present in wood.

\section{Membrane Technology for Recovery of Value-Added Products}

The recovery of lignin is particularly important because it has many applications. It is used to produce value added products such as wood glue and wetting agents. Lignin is also used as versatile raw material that can be used to manufacture many valuable products including vanillin, vanillic acid, synthetic tannins and polymer film. Although several methods have been developed to recover lignin from solution, membrane technology serves as a promising method to achieve efficient lignin recovery. Current approaches for the recovery of lignin using Ultrafiltration, Microfiltration and Nanofiltration are reported elsewhere [71-89].

In 1988 recovery of lignin by membrane filtration was carried out as one of the first published work [90] where the authors investigated the chemical reactivity of lignin as a copolymer during the production of phenolic plastics as well as the separation of high molecular weight lignin using a $10 \mathrm{kDa}$ polysulfone membrane. It was investigated that lignin concentration increases in the retentate by $174 \%$ on applying permeate /concentrate ratio of four with a resulting lignin purity of $63 \%$ in the concentrate and $17 \%$ in the retentate. Later, study was carried out on diafiltrating of black liquor which was achieved using a plate and frame model of $0.36 \mathrm{~km}^{2}$ polymeric membrane with MWCO values from 6-50kDa maintained at a temperature of $60^{\circ} \mathrm{C}[71,72]$. They recovered about $54 \%$ of the initial lignin concentration with an average membrane flux of $90 \mathrm{Lm}^{-2} \mathrm{~h}^{-1}$ using the membrane with molecular weight cut off (MWCO) of $2 \mathrm{kDa}$. The defiltration of black liquor for separation of lignin was also carried out using polysulfone and polusulfone UF membranes with MWCO values of 4, 8 and $20 \mathrm{kDa}$ at a temperature of $60^{\circ} \mathrm{C}$ with cross flow velocity of $4 \mathrm{~ms}^{-1}$ and a transmembrane pressure (TMP) of 1-7 bar [80]. It was observed that a membrane with a higher MWCO increases the purity of the recovered lignin whereas membrane with a low MWCO is effective to achieve a high lignin concentration. Further study on ability of UF for selective separation of lignin was carried out using tubular ceramic membranes with MWCO value of 5, 10 and 15kDa [82]. Analytical results showed that UF with ceramic membrane is effective for lignin fractionation in black liquor. With increasing MWCO value of ceramic membrane during UF, the polydispersity and the average molar mass of lignin fraction decreases. Analytical results such as FTIR, thermal analysis and H-NMR showed that lignin recovered during UF facilitates higher purity. Padilla et al. [76] investigated the ultrafiltration of diluted black liquor. UF was carried out with dilute black liquor with a $100 \mathrm{kDa}$ polysulfone membrane. Then the permeate of this filtration step was used as a feed for the next filtration step with $30 \mathrm{kDa}$ polysulfone membrane. The procedure was repeated for $10 \mathrm{kDa}$ polysulfone and $5 \mathrm{kDa}$ and $1 \mathrm{kDa}$ cellulose acetate membrane.

Later study was also carried out for the behaviour of fractionated and ultra-filtrated black liquor relating to the glass transition temperature and chemical composition [91]. This study showed that UF of black liquor allows selective extraction of lignin fraction with thermo-mechanical properties. Toledano et al. [92] studied the separation of lignin fractions from the black liquor using ultrafiltration. The black liquor resulting from the alkaline pulping of the Miscanthus sinensis was subjected to several stages of ultrafiltration using ceramic membranes of different cut offs (5, 10 and $15 \mathrm{kDa}$ ). The permeates obtained during UF was analysed and the lignin is isolated by acid precipitation ultrafiltration was found to be an effective process for lignin fractionation and separation. Weinwurm et al. [93] carried out experiment on nanofiltration of organosolv liquors for lignin separation and production. After organosolv treatment the nanofiltration was carried out and observed that the flux of the membrane tends to decline with increasing lignin concentration. A rejection of $99 \%$ was achieved with the NF membrane and thus NF was found to be a promising option to separate lignin. 


\section{Recovery of Ionic Liquids by Membrane Filtration}

Ionic liquids are excellent but expensive solvents to dissolve lignocelluloses, therefore the recovery and reuse of IL is very important. The recovery of IL is generally done through distillation of anti-solvents from ILs under vacuum which is usually a very energy extensive process. Usually it is presumed that ILs cannot be purified and recovered cost effectively in large scale processes. During the last two decades membrane filtration has been gaining great importance for the purification and recovery of IL. Nanofiltration seems to be a versatile method for the recovery of ILs used during the processing of biomass because the nanofiltration membranes can be selected properly according to the required purpose, either to retain the IL or to allow it to pass through the membrane [94]. As ILs consists of ions, nanofiltration has become an interesting alternative for downstream processing the performance of which is based on several solute-membrane interaction mechanisms [95]. NF membranes can separate charged and neutral compounds or mono- and divalent ions in which the retention depends on the charge and size of the molecules and ions. There are two possible ways of separating IL and other components,

a) The retention of the components and permeation of the IL through the membrane.

b) The retention of the IL and the permeation of the product.

Whether the possibility (a) and (b) to be used depends on the membrane property, size, charge and solubility of the components and the ionic liquid [94]. Krockel et al. [94] first reported on the application of nanofiltration for separation of mixtures containing IL. They found that retention of ILs upto 82\% and 95\% were obtained for 1-butyl-3-methyl imidazolium tetrafluoroborate and 1-butyl-3-methyl imidazolium sulphate respectively using commercial Desal membrane. However recent study by Wu et al. [96] in 2009 obtained retention values of only $60 \%$ and $67 \%$ for 1 -butyl-3-methyl imidazolium tetrafluoroborate and 1-butyl-3-methyl imidazolium bromide respectively. Abels et al. [97] investigated the feasibility of ionic liquid purification via nanofiltration membranes with regards to permeate flux and rejection performance.

They used two commercially available polyamide and polyimide membranes to separate saccharides from IL (1,3-dimethyl imiadzolium dimethyl phosphate) and found that at high concentration of IL there is a marked decrease in permeate flux for all the membranes due to low permeabilities of IL. At low feed concentration of IL, the concentration of product in the permeate is significantly lower in case of polyamide membranes than with the polyimide membranes. They concluded that nanofiltration is a feasible process to recover IL up to a purity of $80 \%$. Hazarika et al. [98] also demonstrated that recovery of ionic liquid can be obtained with nanofiltration membrane in which the ionic liquid is obtained as the reject in high concentration and more than $50 \%$ rejection was obtained. Avram et al. [99] studied the development of nanofiltration membranes for ionic liquid recovery. NF membrane was developed by interfacial polymerization using base
PES ultrafiltration membranes. They studied the ability of the NF membrane to concentrate low molecular weight sugars while recovering the dissolved ILs in aqueous solution in the permeate and found that the selectivity for 1-butyl-3-methyl imidazolium chloride over glucose is as high as 36.6 and the membrane permeance was $2.31 \mathrm{Lm}^{-2} \mathrm{~h}^{-1} \mathrm{bar}^{-1}$

In general, the use of membrane technology for IL recovery is regarded as advantageous in comparison to other separation methods.

\section{Summary}

Lignocellulosic biomass is an abundant renewable feedstock for energy and chemical production. Therefore, processing of lignocellulosic biomass provides a great opportunity to produce various value-added products. This review shows that IL pre-treatment of lignocellulosic biomass is very effective tool for fractionation of lignocellulosic biomass and thus to obtain lignin. However more exploitation of ILs in the lignocellulosic biomass processing is required to find the better understanding and the effectiveness of ILs to extract lignin.

The recovery of lignin is very important because it has many applications and membrane technology has been investigated as an economical and environmentally beneficial platform for the recovery of lignin. At the same time ILs used in the processing of lignocellulosic biomass is very expensive therefore recovery and reuse of IL is very important and, in this regard, nanofiltration seems to be a versatile method for the recovery of ILs.

\section{References}

1. Costa Lopes AM, Joao KG, Morais ARC, Lukasik EB, Lulasik RB (2013) Ionic liquid as a tool for lignocellulosic biomass fractionation. Sustainable Chemical Processes 1:3.

2. Brandt A, Grasvik J, Hallett JP, Welton T (2013) Deconstruction of lignocellulosic biomass with ionic liquids. Green Chemistry 15(3): 550-583.

3. Zhang YP (2008) Reviving the carbohydrate economy via multiproduct lignocellulose biorefineries. J Ind Microbiol Biotechnol 35(5): 367-375.

4. Ragauskas AJ, Williams CK, Davison BH, Britovsek G, Cairney J, et al. (2006) The path forward for biofuels and biomaterials. Science 311(5760): 484-489.

5. Clark JH (2007) Green chemistry for the second generation biorefinery sustainable chemical manufacturing based on biomass. Journal of Chemical Technology and Biotechnology 82(7): 603-609.

6. McKendry P (2002) Energy production from biomass (part1): overview of biomass. Bioresour Technol 83(1): 37-46.

7. Lynd LR, Weimer PJ, van Zyl WH, Pretorius IS (2002) Microbial cellulose utilisation: Fundamentals and biotechnology. Microbiol Mol Biol Rev 66(3): 506-577.

8. Mai C, Kües U, Militz H (2004) Biotechnology in the wood industry. Appl Microbiol Biotechnol 63(5): 477-494.

9. Hon DNS, Shiraishi N (1991) Wood and cellulosic chemistry, second edition, M. Dekkar Inc, New York, p. 1020.

10. Whetten RW, MacKay JJ, Sederoff RR (2003) Recent Advances in understanding lignin biosynthesis. Annu Rev Plant Physiol Plant Mol Biol 49: 585-609. 
11. Li Q He YC, Xian M, Jun G, Xu X, et al. (2009) Improving enzymatic hydrolysis of wheat straw using ionic liquid 1-ethyl-3-methyl imidazolium diethyl phosphate pretreatment. Bioresour Technol 100(14): 3570-3575.

12. Arora R, Manisseri C, Li C, Ong MD, Scheller HV, et al. (2010) Monitoring and analyzing process streams towards understanding ionic liquid pretreatment of switchgrass (Panicum virgatum L.). BioEnergy Research 3(2): 134-145.

13. Stark A (2011) Ionic Liquids in the biorefinery: a critical assessment of their potential. Energy Environmental Science 4(1): 19-32.

14. Swatloski RP, Spear SK, Holbrey JD, Rogers RD (2002) Dissolution of cellulose with ionic liquids. Journal of American Chemical Society 124(18): 4974-4975.

15. Lee SH, Doherty TV, Linhardt RJ, Dordick JS (2009) Ionic liquid mediated selective extraction of lignin from wood leading to enhanced enzymatic cellulose hydrolysis. Biotechnol Bioeng 102(5): 1368-1376.

16. Zhang H, Wu J, Zhang J, He JS (2005) 1-Allyl-3-methylimidazolium chloride room temperature ionic liquid: A new and powerful non-derivatizing solvent for the cellulose. Macromolecules 38(20): 8272-8277.

17. Fort DA, Remsing RC, Swatloski RP, Moyna P, Moyna G, et al. (2007) Can ionic liquids dissolve wood? Processing and analysis of lignocellulosic materials with 1-n-butyl-3-methylimidazolium chloride. Green Chemistry 9: 63-69.

18. Olivier-Bourbigou H, Magna L, Morvan D (2010) Ionic liquids and catalysis: Recent progress from knowledge to applications. Applied Catalysis A: General 373(1-2): 1-56.

19. Dadi AP, Schall CA, Varanasi S (2007) Mitigation of cellulose recalcitrance to enzymatic hydrolysis by ionic liquid pretreatment. Appl Biochem Biotechnol 137-140(1-12): 407-421.

20. Li C, Knierim B, Manisseri C, Arora R, Scheller HV, et al. (2010) Comparison of dilute acid and ionic liquid pretreatment of switchgrass: biomass recalcitrance, delignification and enzymatic saccharification. Bioresource Technology 101(13): 4900-4906.

21. Flieger J, Grushka EB, Zelazko AC (2014) Ionic liquids as solvents in separation processes. Austin journal of analytical and pharmaceutical chemistry.

22. Neves CM, Ventura SP, Freire MG, Marrucho IM, Coutinho JA (2009) Evaluation of cation influence on the formation and extraction capability of ionic liquid based aqueous biphasic systems. J Phys Chem B 113(15): 5194-5199.

23. Tadesse H, Luque R (2011) Advances on biomass pretreatment using ionic liquids: An overview. Energy Environment Sci 4(10): 3913-3929.

24. Kilpeläinen I, Xie H, King A, Granstrom M, Heikkinen S, et al. (2007) Dissolution of wood in ionic liquids. J J Agric Food Chem 55(22): 91429148.

25. Lan W, Liu CF, Sun RC (2011) Fractionation of bagasse into cellulose, hemicelluloses, and lignin with ionic liquid treatment followed by alkaline extraction. Journal of Agricultural Food Chemistry 59(16): 86918701.

26. Yang D, Zhong LX, Yuan TQ, Peng XW, Sun RC (2013) Studies on the structural characterization of lignin, hemicelluloses and cellulose fractionated by ionic liquid followed by alkaline extraction from bamboo. Industrial Crops and Products 43: 141-149.

27. Fu D, Mazza G, Tamaki Y (2010) Lignin extraction from straw by ionic liquids and enzymatic hydrolysis of the cellulosic residues. J Agric Food Chem 58(5): 2915-2922.

28. Sun N, Mafizur R, Qin Y, Maxim ML, Rodriguez H, et al. (2009) Complete dissolution and partial delignification of wood in the ionic liquid 1-ethyl-3-methylimidazolium acetate. Green Chemistry 11(5): 646-655.
29. Singh S, Simmons BA, Vogel KP (2009) Visualization of biomass solubilization and cellulose regeneration during ionic liquid pretreatment of switchgrass. Biotechnol Bioeng 104(1): 68-75.

30. Doherty TV, Mora-Pale M, Foley SE, Linhardt RJ, Dordick JS (2010) Ionic liquid solvent properties as predictors of lignocellulose pretreatment efficacy. Green Chemistry (11): 1967-1975.

31. Brandt A, Ray MJ, To TQ, Leak DJ, Murphy RJ, et al. (2011) Ionic liquid pretreatment of lignocellulosic biomass with ionic liquid-water mixtures. Green Chemistry 13(9): 2489-2499.

32. Shamsuri AA, Abdullah DK (2010) Isolation and characterization of lignin from rubber wood in ionic liquid medium. Modern Applied Science 4(11): 19-27.

33. Lynam JG, Toufiq Reza M, Vasquez VR, Coronella CJ (2012) Pretreatment of rice hulls by ionic liquid dissolution. Bioresource Technology 114: 629-636.

34. Dadi AP, Varanasi S, Schall CA (2006) Enhancement of cellulose saccharification kinetics using an ionic liquid pretreatment step. Biotechnol Bioeng 95(5): 904-910.

35. Zavrel M, Bross D, Funke M, Büchs J, Spiess AC (2009) High throughput screening for ionic liquids dissolving (ligno-) cellulose. Bioresour Technol 100(9): 2580-2587.

36. Vo HT, Kim CS, Ahn BS, Kim HS, Lee H (2011) Study on dissolution and regeneration of poplar wood in imidazolium based ionic liquids. Journal of Wood Chemistry and Technology 31: 89-102.

37. Yoon LW, Ngoh GC, Chua M, Seak A, Hashim M (2011) Comparison of ionic liquid, acid and alkali pretreatments for sugarcane bagasse enzymatic saccharification. Journal of Chemical Technology and Biotechnology 86(10): 1342-1348.

38. Simmons BA, Singh S, Holmes BM, Blanch HW (2010) Ionic liquid pretreatment. Chemical Engineering Progress 106: 50-55.

39. Fukaya Y, Sugimoto A, Ohno H (2006) Superior solubility of polysaccharides in low viscosity, polar, and halogen free 1,3-dialkylimidazolium formates. Biomacromolecules 7(12): 3295-3297.

40. Kamlet MJ, Taft RW (1976) The solvatochromic comparison method I. Beta-scale of solvent hydrogen-bond acceptor ( $\mathrm{Hba}$ ) basicities. Journal of American Chemical Society 98(2): 377-383.

41. Taft RW, Kamlet MJ (1976) Solvatochromic comparison method II. Alpha-scale of solvent hydrogen-bond donor ( $\mathrm{Hbd}$ ) acidities. Journal of American Chemical Society 98(10): 2886-2894.

42. Brandt A, Hallett JP, Leak DJ, Murphy RJ, Welton T (2010) The effect of the ionic liquid anion in the pretreatment of pine wood chips. Green Chemistry 12(4): 672-679.

43. Wang X, Li H, Cao Y, Tang Q (2011) Cellulose extraction from wood chip in an ionic liquid 1-allyl-3-methylimidazolium chloride (AmimCl). Bioresource Technology 102(17): 7959-7965.

44. Shill K, Padmanabhan S, Xin Q, Prausnitz JM, Clark DS, et al. (2011) Ionic liquid pretreatment of cellulosic biomass: enzymatic hydrolysis and ionic liquid recycle. Biotechnol Bioeng 108(3): 511-520.

45. Casas A, Palomar J, Alonso MV, Oliet M, Omar S, et al. (2012) Comparison of lignin and cellulose solubilities in ionic liquids by COSMO-RS analysis and experimental validation. Industrial Crops and Products 37(1): 155-163.

46. Remsing RC, Swatloski RP, Rogers RD, Moyna G (2006) Mechanism of cellulose dissolution in the ionic liquid 1-n-butyl-3-methylimidazolium chloride: a 13C and 35/37 Cl NMR relaxation study on model systems. Chem Commun (Camb) (12): 1271-1273.

47. Feng L, Chen ZI (2008) Research progress on dissolution and functional modification of cellulose in Ionic liquids. Journal of Molecular Liquids 142(1-3): 1-5. 
48. Zhang J, Zhang H, Wu J, Zhang J, He J, Xiang J (2010) NMR spectroscopic studies of cellobiose solvation in EmimAc aimed to understand the dissolution mechanism of cellulose in ionic liquids. Phys Chem Chem Phys 12(8): 1941-1947.

49. Kosan B, Michels C, Meister F (2008) Dissolution and forming of cellulose with ionic liquids. Cellulose 15(1): 59-66.

50. Ning S, Mustafizur R, Ying Q Mirela LM, Hector R, et al. (2009) Complete solution and partial delignification of wood in the ionic liquid 1-ethyl-3-methylimidazolium acetate. Green Chemistry 11: 646-655.

51. Janesko BG (2011) Modelling Interactions between lignocelluloses and ionic liquids using DFT-D. Physical Chemistry Chemical Physics 13(23): 11393-11401.

52. George A, Tran K, Morgan TJ, Benke PI, Berrueco C, et al. (2011) The effect of ionic liquid cation and anion combinations on the macromolecular structure of lignins. Green Chemistry 13(12): 3375-3385.

53. Pu YQ Jiang N, Ragauskas AJ (2007) Ionic liquids as a green solvent for lignin. Journal of Wood Chemistry and Technology 27: 23-33.

54. Liu H, Sale KL, Holmes BM, Simmons BA, Singh S (2010) Understanding the interactions of cellulose with ILs: A molecular dynamics study. J Phys Chem B 114(12): 4293-4301.

55. Binder JB, Gray MJ, White JF, Zhang ZC, Holladay JE (2009) Reactions of lignin model compounds in ionic liquids. Biomass and Bioenergy 33(9): 1122-1130.

56. Kimon KS, Leslie Alan E, Sinclair DWO (2011) Enhanced saccharification kinetics of sugarcane bagasse pretreated in 1-butyl-3-methylimidazolium chloride at high temperature and without complete dissolution. Bioresour Technol 102(19): 9325-9329.

57. Tan SSY, MacFarlane DR, Upfal J, Edye LA, Doherty WOS, et al. (2009) Extraction of lignin from lignocellulose at atmospheric pressure using alkylbenzenesulfonate ionic liquid. Green Chemistry 11(3): 339-345.

58. Pezoa R, Cortinez V, Hyvarinen S, Reunanen J, Linenqueo ME, et al (2010) Use of ionic liquids in the pretreatment of forest and agricultural residues for the production of bioethanol. Cellulose Chemistry and Technology 44(4-6): 165-172.

59. Xu F, Shi YC, Wang D (2012) Enhanced production of glucose and xylose with partial dissolution of corn stover in ionic liquid, 1-Ethyl-3-methylimidazolium acetate. Bioresour Technol 114: 720-724.

60. Wyman CE, Dale BE, Elander RT, Holtzapple M, Ladisch MR, et al (2005) Coordinated development of lignocellulosic biomass pretreatment technologies. Bioresour Technol 96(18): 1959-1966.

61. Mosier N, Wyman C, Dale B, Elander R, Lee YY, et al. (2005) Features of promising technologies for pretreatment of lingocellulosic biomass. Bioresour Technol 96(6): 673-686.

62. Bahcegul E, Apaydin S, Haykir NI, Tatli E, Bakir U (2012) Different ionic liquids favor different lignocellulosic biomass particle sizes during pretreatment to function efficiently, Green Chemistry 14: 1896-1903.

63. Nguyen TA, Kim KR, Han SJ, Cho HY, Kim JW, et al. (2010) Pretreatment of rice straw with ammonia and ionic liquid for lignocelluloses conversion to fermentable sugars. Bioresour Technol 101(19): 7432-7438.

64. Fu D, Mazza G (2011) Aqueous ionic liquid pretreatment of straw. Bioresour Technol 102(13): 7008-7010.

65. Hou XD, Li N, Zong MH (2013) Significantly enhancing enzymatic hydrolysis of rice straw after pretreatment using renewable ionic liquid-water mixtures. Bioresource Technology 136: 469-474.

66. Zhang Z, O’Hara IM, Doherty WO (2012) Pretreatment of sugarcane bagasse by acid-catalysed process in aqueous ionic liquid solutions. Bioresour Technol 120: 149-156.
67. Wei L, Li K, Ma Y, Hou X (2012) Dissolving lignocellulosic biomass in a 1-butyl-3-methylimidazolium chloride-water mixture. Industrial Crops and Products 37: 227-234.

68. Zhang YT, Du HB, Qian XH, Chen EYX (2010) Ionic liquid-water mixtures: enhanced $\mathrm{K}_{\mathrm{w}}$ for efficient cellulosic biomass conversion. Energy Fuels 24(4): 2410-2417.

69. Ma YC, Wei LG, Li KL, Wang SJ, Yu JY, et al. (2009) Separating lignin and cellulose from lignocellulosic biomass using an aqueous ionic liquid solution (Chinese). Patent, 200910012002.

70. Zhang ZY, O’Hara IM, Doherty WO (2013) Effects of pH on pretreatment of sugarcane bagasse using aqueous imidazolium ionic liquids. Green chemistry 15(2): 431-438.

71. Uloth VC, Wearing JT (1989) Kraft Lignin Recovery: Acid Precipitation Versus Ultrafiltration, Part II: Technology and economics. Pulp and Paper Canada 90: T357-T360.

72. Uloth VC, Wearing JT (1989) Kraft Lignin Recovery: Acid Precipitation Versus Ultrafiltration, Part I: Laboratory Test Results. Pulp Paper Can 90: T310-T314.

73. Satyanarayana SV, Bhattacharya PK, De S (2000) Flux decline during ultrafiltration of kraft black liquor using different flow modules: A comparative study. Separation and Purification Technology 20(2-3): 155-167.

74. De S, Bhattacharya PK (1996) Flux prediction of black liquor in cross flow ultrafiltration using low and high ejecting membranes. Journal of Membrane Science 109: 109-123.

75. Bhattacharjee S, Datta S, Bhattacharjee C (2006) Performance study during ultrafiltration of Kraft black liquor using rotating disk membrane module. Journal of Cleaner Production 14(5): 497-504.

76. Padilla V, Rangel MG, Bullon J, Rodríguez-Malaver A, Gonzalez AM, et al. (2002) Surface Activity of Lignin Fractions Obtained by Membrane-Separation Technologies of Industrial Black Liquors. Iberoam Congr Pulp Pap Res 10: 10-12.

77. Bhattacharya PK, Todi RK, Tiwari M, Bhattacharjee C, Bhattacharjee S, et al. (2005) Studies on ultrafiltration of spent sulfite liquor using various membranes for the recovery of lignosulphonates. Desalination 174(3): 287-297.

78. Ringena O, Saake B, Lehnen R (2005) Isolation and fractionation of lignosulfonates by amine extraction and ultrafiltration: A comparative study. Holzforschung 59(4): 405-412.

79. Area MC, Martos MS, Felissia FE, Venica AD, Valade JL (2000) Upgrading Spent Liquors from Nssc Process III. Separation of Spent Liquors Components by Ultrafiltration. Cellul Chem Technol 34: 173-182.

80. Wallberg 0, Jonsson AS (2006) Separation of lignin in kraft cooking liquor from a continuous digester by ultrafiltration at temperatures above $100^{\circ} \mathrm{C}$. Desalination 195(1-3): 187-200.

81. Giummarella N, Lindgren C, Lindstrom M, Henriksso G (2016) Lignin prepared by ultrafiltration of black liquor: Investigation of solubility, viscosity, and ash content. Bio Resources 11: 3494-3510.

82. Toledano A, Serrano L, Garcia A, Mondragon I, Labidi J (2010) Comparative study of lignin fractionation by ultrafiltration and selective precipitation. Chemical Engineering Journal 157(1): 93-99.

83. Wallberg O, Jonsson AS, Wimmerstedt R (2003) Fractionation and concentration of kraft black liquor lignin with ultrafiltration. Desalination 154(2): 187-199.

84. Niemi H, Lahti J, Hatakka H, Karki S, Rovio S, et al. (2011) Fractionation of organic and inorganic compounds from black liquor by combining membrane separation and crystallization. Chemical Engineering and Technology 34(4): 593-598. 
85. Pateraki C, Ladakis D, Stragier L, Verstraete W, Kookos I, et al. (2016) Pretreatment of spent sulphite liquor via ultrafiltration and nanofiltration for bio-based succinic acid production. Journal of Biotechnology 233: 95-105.

86. Keyoumu A, Sjodahl R, Henriksson G, Ek M, Gellerstedt G, et al. (2004) Continuous nano- and ultra-filtration of kraft pulping black liquor with ceramic filters. Industrial Crops and Products 20(2): 143-150.

87. Liu G, Liu Y, Ni J, Shi H, Qian Y (2004) Treatability of kraft spent liquor by microfiltration and ultrafiltration. Desalination 160: 131-141.

88. Dafinov A, Font J, Valls RG, (2005) Processing of black liquors by UF/NF ceramic membranes. Desalination 173(1): 83-90.

89. Ebrahimi M, Busse N, Kerker S, Schmitz O, Hilpert M, et al. (2015) Treatment of the Bleaching Effluent from Sulfite Pulp Production by Ceramic Membrane Filtration. Membranes (Basel) 6(1): E7.

90. Olivares M, Guzmán JA, Natho A, Saavedra A (1988) Kraft lignin utilization in adhesives. Wood Sci Technol 22(2): 157-165.

91. Sevastyanova O, Helander M, Chowdhury S, Lange H, Wedin H, et al. (2014) Tailoring the molecular and thermo-mechanical properties of kraft lignin by ltrafiltration. J Appl Polym Sci 131(18): 40799(1)$40799(11)$.

92. Toledano A, Garcia A, Mondragon I, Labidi J (2010) Lignin separation and fractionation by ultrafiltration. Separation and Purification Technology 71(1): 38-43.
93. Weinwurm F, Drljo A, Friedl A (2015) Lignin concentration by nanofiltration and precipitation in a lignocellulose biorefinery. Chemical Engineering Transactions 45: 901-906.

94. Krockel J, Kragl U (2003) Nanofiltration for the separation of non-volatile products from solutions containing ionic liquids. Chem Eng Technol 26(11): 1166-1168.

95. Fernández JF, Jastorff B, Störmann R, Stolte S, Thöming J (2011) Thinking in terms of structure-activity-relationships (T-SAR): A tool to better understand nanofiltration membranes. Membranes (Basel) 1(3): 162183.

96. Wu B, Zhang YM, Wang HP (2009) Non-equilibrium thermodynamic analysis of transport properties in the nanofiltration of ionic liquid-water solutions. Molecules 14: 1781-1788.

97. Abelsa C, Redepenninga C, Mollb A, Melina T, Wesslinga M (2012) Simple purification of ionic liquid solvents by nanofiltration in biorefining of lignocellulosic substrates. Journal of Membrane Science 405- 406:110.

98. Hazarika S, Dutta NN, Rao PG (2012) Dissolution of lignocelluloses in ionic liquids and its recovery by nanofiltration membrane. Separation and Purification Technology 97: 123-129.

99. Avram AM, Ahmadiannamini P, Qian X, Wickramasinghe SR (2017) Nanofiltration membranes for ionic liquid recovery. Separation Science and Technology 52(13): 2098-2107.

\section{Your next submission with Juniper Publishers} will reach you the below assets

- Quality Editorial service

- Swift Peer Review

- Reprints availability

- E-prints Service

- Manuscript Podcast for convenient understanding

- Global attainment for your research

- Manuscript accessibility in different formats

( Pdf, E-pub, Full Text, Audio)

- Unceasing customer service

Track the below URL for one-step submission https://juniperpublishers.com/online-submission.php 